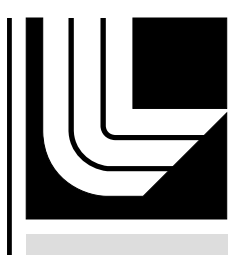

LAW RENCE LIVERMORE N A TIO N A L LABORATORY

\title{
Review of LLNS Contractor Assurance System (CAS)
}

J. E. Johnston, M. Litus, S. Metta, W. Luce

January 29, 2008 
This document was prepared as an account of work sponsored by an agency of the United States government. Neither the United States government nor Lawrence Livermore National Security, LLC, nor any of their employees makes any warranty, expressed or implied, or assumes any legal liability or responsibility for the accuracy, completeness, or usefulness of any information, apparatus, product, or process disclosed, or represents that its use would not infringe privately owned rights. Reference herein to any specific commercial product, process, or service by trade name, trademark, manufacturer, or otherwise does not necessarily constitute or imply its endorsement, recommendation, or favoring by the United States government or Lawrence Livermore National Security, LLC. The views and opinions of authors expressed herein do not necessarily state or reflect those of the United States government or Lawrence Livermore National Security, LLC, and shall not be used for advertising or product endorsement purposes.

This work performed under the auspices of the U.S. Department of Energy by Lawrence Livermore National Laboratory under Contract DE-AC52-07NA27344. 


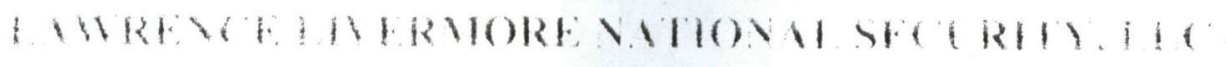

ASSESS, IMPROVE, AND MODERNIZE REPORT

Review of LLNS Contractor Assurance System (CAS)

Document Number: $L L N L-T R-400830$

Revision: Final

Date of Assessment: December 10-13, 2007

FMA Team Leader: William Luce, Contractor Assurance Process Manager, Washington Savannah River Company, LLC.

Reviewed By: $\quad$ LLNS, LLC Office

Contractor Assurance Office

PAD:

Steve Johnson, Contractor Assurance Officer

LLNS, LLC Point-of-Contact:

Trey Johnston

Approved for the FMA Team:

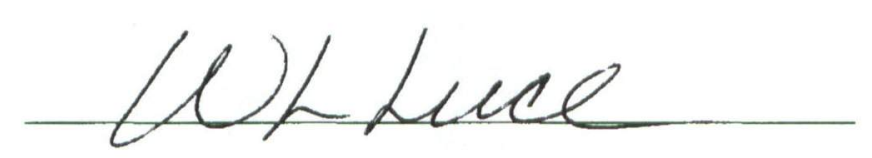

William Luce

Washington Savannah River Company, LLC.

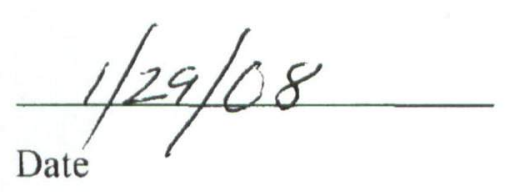

Date 


\section{Assess, Improve, and Modernize (AIM) Team}

Review of LLNS Contractor Assurance System (CAS)

Review Document Number: LLNL-TR-400830

Conducted 12/10/07 through 12/13/07 
This document was prepared as an account of work sponsored by an agency of the United States government. Neither the United States government nor Lawrence Livermore National Security, LLC, nor any of their employees makes any warranty, expressed or implied, or assumes any legal liability or responsibility for the accuracy, completeness, or usefulness of any information, apparatus, product, or process disclosed, or represents that its use would not infringe privately owned rights. Reference herein to any specific commercial product, process, or service by trade name, trademark, manufacturer, or otherwise does not necessarily constitute or imply its endorsement, recommendation, or favoring by the United States government or Lawrence Livermore National Security, LLC. The views and opinions of authors expressed herein do not necessarily state or reflect those of the United States government or Lawrence Livermore National Security, LLC, and shall not be used for advertising or product endorsement purposes.

This work performed under the auspices of the U.S. Department of Energy by Lawrence Livermore National Laboratory. 


\section{Executive Summary}

The focus of the review was to evaluate the LLNS Contractor Assurance System (CAS) system description document and implementation plan. The team reviewed the description document and the near and long term strategy improvement plans for the defined enhancements to the LLNS CAS. Review emphasis was placed on the CAS functional elements of Assessments, Issues Management, and Performance Measures, as well as the related CAS attributes of Requirements, Policies and Procedures, Risk Methodology, and Continuous Improvement. The approach taken by the team was to review the pertinent LLNS CAS documents, interview key CAS Process Owners, and interview selected line managers. The reviews were conducted in such a manner to achieve an understanding of the overall objective of the CAS and the processes within; and the soundness of the improvement plans for each of the elements/related attributes. The team then identified suggested recommendations for consideration as the overall implementation process for improvements moves forward.

The team appreciates the work that went into the development of the CAS Implementation Plan. It provided a meaningful starting place for this AIM team as it included sufficient information to quickly gain an understanding of the current LANS CAS processes and improvement initiatives.

The team found that the July 2007 CAS Description Document did not provide a level of detail which would provide the reader an understanding of the elements and attributes of the CAS, how they are integrated, and how they help Managers manage the performance of their activities. Consider revising the document to include a level of detail that would provide value to the LLNS Board of Governors, LSO, and LLNS Managers. The team also found the description document to focus almost exclusively on describing the LLNS approach and initiatives associated with the 17 key attributes of Contract Clause $\mathrm{H}-4$. While these discussions are appropriate for inclusion in the description document, by themselves, they do not clearly address the requirements and criteria in Attachment 1 and Appendix A to DOE O 226.1A. It would seem that a comprehensive written CAS description document would address not only the expectations of Clause $\mathrm{H}-4$, but that it would also address the requirements and criteria from DOE O 226.1A.

The staff of the Contractor Assurance Office was found to be very knowledgeable of the CAS elements, the current status of these elements, and was excited and energetic with respect to the improvement plans and initiatives. This is a very strong combination for going forward and the staff seems to be teaming well for successful integration. 


\section{AlM Team Members}

The following individuals were team members for this AIM:

Marty Litus, Six Sigma Program Manager, Bechtel BWXT Idaho, LLC.

William Luce, Contractor Assurance Process Manager, Washington Savannah River Company, LLC.

Stephen Metta, Contractor Assurance Division Manager, Los Alamos National Security, LLC.

\section{Scope}

Review the LLNS CAS system description document and implementation plans and make recommendations.

\section{Purpose}

To understand and implement the LLNS parent organizations' best practices in a timely and costeffective manner.

\section{Persons Contacted or Interviewed}

Refer to Attachment A for a list of persons contacted or interviewed by the AIM team.

\section{Documents Reviewed}

Refer to Attachment B for a list of documents reviewed by the AIM team.

\section{Description of Areas Reviewed}

Assessments

Issues Management

Performance Measures

Requirements, Policies and Procedures

Risk Methodology

Continuous Improvement 
Governance

Customer Transparency

\section{Review Results}

\section{Assessments}

In the Assessment arena, CAS (through DOE O 226.1A) generally relates to activities including self-assessments or management assessments, operational awareness or management walkthrough, quality assurance, and internal independent assessments. Whatever the exact composition of the activities that constitutes the LLNS Assessment Program; it is important that the composition be clearly defined in the CAS description document and appropriately interfaced/integrated with other management programs that specify assessments, such as the Quality Assurance Program, Emergency Management Program and Conduct of Operations.

\section{Suggestions for improvement:}

When establishing the exact composition of the LLNS Assessment Program and pursing the initiatives outlined in the CAS Implementation Plan, the team suggests the following attributes and recommendations be given consideration:

- LLNS has appropriately identified a desire to reduce the overall assessment burden and coordinate assessment activities, while ensuring completion of regulatory required assessments. This naturally points to a need to fully integrate (to the extent practical) all Internal Independent Assessments such that a single assessment of a facility/operation or support organization satisfies the scope and frequency requirements from the myriad of drivers. Whether implemented through a dedicated team of individuals that can cover the necessary disciplines, or implemented through teams that are brought together for a specific assessment, or some combination of both, participating individuals will need to be clearly independent of the activities they are assessing and trained and qualified to a documented standard.

- It should not be expected that every independent assessment/audit activity will be appropriate for direct inclusion into an integrated team approach. Some quality assurance audits (driven by QC-1 and similar requirements) require Lead QA Auditors to perform audits on frequencies that will not generally align with an integrated team approach. Similarly, some financial/contract audit activities will not typically align. These types of audits should still be credited as part of the overall LLNS Assessment Program.

- Self-Assessments by line organizations are an important element of any contractor assessment program. (Line organizations in this context broadly include all aspects of operations and all support activities.) Tailored or graded approaches with strong management involvement are imperative for effective self-assessment activities. This area is especially prone to excessive and often non-value added efforts. Therefore, care should 
be taken to structure the requirements for self-assessments generally based on well defined factors (with risk considerations) including:

- Specific regulatory or contractually driven requirements for assessments that can be satisfied through self-assessments,

- Performance (areas identified by line management, areas identified by Internal Independent Assessments, and areas identified by external assessments),

- Senior management (Director/Principle Associate Directors) directed assessments, and

- Line management discretionary self-assessments ideally focused on a particular process or aspect of a process that is important to successful operations.

- The concept of Management Assessments is often found to be difficult to clearly define and can also be a source of multiple non-integrated activities that can be seen as a burden to line organizations. It was explained to the team that Management Assessments were to focus on the adequacy and effectiveness of institutional programs (e.g., Radiological Protection) where the manager of each program would conduct an adequacy assessment (i.e., whether the processes and procedures continue to be appropriate) and also conduct an effectiveness assessment of field implementation of the program. Given the overlaps that such activities have with Internal Independent Assessments and Self-Assessments, it is recommended that institutional assessments of the adequacy of programs be considered Self-Assessments. Any necessary institutional effectiveness assessments of field implementation should be integrated with Internal Independent Assessments. Elements of an Assessment Program that can be more clearly understood as Management Assessments, but different from Internal Independent Assessment and Self-Assessments are probably better credited through Management Observations (and important element of Human Performance Improvement) and Performance Analysis (a process involving management at all levels reviewing performance metrics, trends, and other information that can identify broad performance issues and areas that require attention).

- When conducting any of the assessment activities under the LLNS Assessment Program, assessors should be using the same set of performance objectives and criteria (or more detailed lines of inquiry when appropriate). The POCs/LOIs should be documented and based on the important elements (smart set) of the processes and procedures (which stem from requirements) used for conducting work.

- When developing the LLNS Issues Management System (discussed below), consideration should be given to including an Assessment Module. Such a module can provide for not only scheduling of assessments, but documentation of POCs/LOls and assessment results. Automatic feeds of information into the Issues Management System and assessment report consistencies can be easily accommodated through such modules.

- When bringing the results of assessments into the Issues Management System, basic business rules will need to be established to ensure consistent data entry. For example, if an overall Finding is supported by three specific examples or symptoms (often the case), a consistent rule is needed to have such conclusions either appear as one issue, two issues, or four issues in the Issues Management System. (Four might be the appropriate business rule as the Finding can often be assigned a higher risk/significance category than the three examples/symptoms.) 


\section{Issues Management}

As indicated in the CAS Implementation Plan and further described by individuals during the AIM team review, LLNS is intending to centralize their issue management processes and upgrade their processes to include necessary elements of a fully effective corrective action program. The activities to date seem to be well targeted to that purpose and included obtaining inputs and informal benchmarks from other sites across the complex. The basic concepts being pursued are fundamentally similar to elements of the processes currently being used at Los Alamos and Savannah River and are further consistent with basic INPO performance objectives and criteria for such systems.

\section{Suggestions for improvement:}

As LLNS pursues implementation of the upgraded Issues Management System, the team suggests the following attributes and recommendations be given consideration:

- It is appropriate to integrate the variety of existing issues management systems into a single system where possible. However, some specific systems will probably be found where total integration is not possible. Certain security event systems and injury/illness systems, which naturally involve personal information and/or classified information, cannot be fully integrated and they will still need to be maintained to satisfy unique requirements. However, when corrective actions (beyond disciplinary actions) for a specific security event or injury/illness are necessary or undesired trends are identified from these systems, inclusion of the issue in the Issue Management System is appropriate. A similar situation will probably arise with equipment issues. The Issues Management System would only typically be entered when issues beyond fixing the equipment are identified or undesired trends are identified.

- A structure including assignment of a Risk (or Significance) Category to each issue that then dictates the applicable elements of the Corrective Action Program is appropriate. It is important that these categories be defined as clearly as possible. The category definitions or guidance should include particular types of issues that (either generally or always) need to be assigned to particular categories.

- Extracting data from the Issues Management System is critical to developing accurate performance metrics and in conducting management analyses of performance. It is important to have some basic understanding of the types of data sorts and reports to be extracted from the system before full implementation to ensure the necessary data fields are included. Some of the critical fields will be functional area type (or issue type), cause codes, and applicability of the issue. LLNS should also consider a way to identify particular issues as being Human Performance Errors to enable collection of data that will be extremely useful as LLNS moves further into the Human Performance Initiatives arena.

- When training on the Issues Management System, ensure training fully covers the corrective action process in additional to training on using the software tool. 
- Management involvement in the Issues Management Process is critical to the appropriate analysis of the issues, identification of appropriate corrective actions, assignments of responsibilities and due dates, etc. The process currently being modeled at LLNS involves Screening Teams and Management Review Boards similar to that currently used at Los Alamos and recommended by INPO. It is a reasonable model that provides for necessary management involvement and also helps ensure data consistency ... a critical element to any metrics or performance analyses that utilize data from the system.

- The structure and flow of issues to the Management Review Board should include some flexibility for particular issues that might not warrant the exact treatment that other issues assigned to the same risk/significance category receive.

- Both Los Alamos and Savannah River make extensive use of "modules" with their respective Issues Management Systems and LLNS may find the concept and utilization of modules to be appropriate and cost-effective for their system. Modules are developed to provide particular paths for issues to enter the Issues Management Systems automatically while consistently documenting the product that led to the identification of the issue. For example, when a Critique of an event is conducted, a module would electronically capture a formatted critique report and permit electronic input of any issues from the report automatically into the Issues Management Systems. Modules are also useful for a process like NCRs, when unique decisions are needed to reject, repair or use the item as is.

\section{Performance Measures}

As indicated in the CAS Implementation Plan, LLNS is pursuing establishment of a comprehensive program to identify, gather, verify, analyze, trend, disseminate, and make use of performance indicators. Part of this includes utilization of Performance Soft Views (PSViews) software which appears to have good capabilities for high level "dashboard" type metrics, as well as lower level metrics that might be able to provide an early alert when a higher level metric is in jeopardy.

\section{Suggestions for improvement:}

As LLNS pursues implementation of the Performance Measures initiatives outlined in the CAS Implementation Plan, the team suggests the following attributes and recommendations be given consideration:

- It might be possible to develop a sufficient set of performance metrics that are sufficient to enable a good analysis of performance for undesired trends and broader issues that warrant management attention. However, some sites currently utilize both performance metrics and formal site-level performance analyses to reach such conclusions. Where site-level performance analyses are used, they often result in identification of new or revised performance metrics that monitor the particular trend/broad issue.

- Performance metrics typically show performance over some period of time with respect to a particular goal and include identification of any actions that need to be taken to meet the goal or to otherwise improve performance with respect to the metric. As is generally 
recognized, metrics in conjunction with management attention often result in meeting goals or improved performance. Care should always be applied to ensure that the metrics selected are those that accurately depict important areas of performance and areas of performance that need improvement and escalated management attention. They should be re-visited on some frequency to ensure they are still the appropriate set. When trending, ensure thresholds or rules are pre-defined (when possible) to declare a trend.

- Consider the use of other metrics when trending where a goal might not be as much the interest as performance within ranges of a control chart or other techniques. Trending of this nature can require broader time spans of data, but are useful in determining areas where performance may be headed in the wrong direction or broader issues are prevalent.

- Many techniques can be used to assess performance. LLNS should consider and adopt those techniques that are useful to management in determining areas that warrant performance attention and resources.

\section{Requirements, Policies and Procedures}

LLNS has a reasonably firm understanding of their path forward in moving to a Standards Based Management System, the necessity of such a system, and has aggressively obtained inputs and informal benchmarks from other sites across the complex. The "tool" from Oak Ridge, when supported with the LLNS database (and ultimately with a fully integrated procedures management system) seems to provide to relatively easy way for workers and others to find procedures and requirements of interest.

Suggestions for improvement:

As LLNS pursues implementation of a SBMS and the other Requirements, Policies and Procedures initiatives outlined in the CAS Implementation Plan, the team suggests the following attributes and recommendations be given consideration:

- The draft flow process for receipt of new/revised Directives from LSO, completion of an analysis of risks and impacts, and response back to LSO seem to be well aligned with organizational responsibilities and comprehensive in identifying potential impacts and costs. Involvement of the Strategic Operations Board (SOB) and a Change Control Board are appropriate, but you will likely find instances where an exact understanding of the impact of a new requirement can be a function of the implementing procedure that is later revised or developed to enable compliance with the requirement. The SOB may want an opportunity to review particular new or revised implementing procedures prior to their issuance to ensure alignment with anticipated cost impact expectations.

- The flow process and procedures for new/revised requirements will need to cover sources other than specific direction from LSO. New or revised Federal, State, and Local laws and regulations must be accommodated as well as "corporate" requirements that might be directed by the LLNS Board. It would also be appropriate to include a flow process and procedural steps for a LLNS desired change to or relief from an existing contractually 
imposed requirement. Such instances will certainly arise, so it is important to have a process in place to accommodate this need. Having the process in place can also be a form of encouragement for the various functional disciplines to look for such opportunities to be cost-effective. Similarly, a process for handling situations where field compliance with requirements has not been achieved is also necessary. This might include some timeframes where LLNS can manage the actions to achieve field compliance without LSO approval, time-frames where LSO approval is necessary and clear process steps for gaining approvals for specific equivalencies and exceptions.

- Alignment of the total set of requirements by functional areas that then further align with organizational responsibilities is an appropriate activity that provides a necessary structural understanding of the thousands of individual requirements that ultimately make up the total set. LLNS may find that this same functional area structure to be appropriate for utilization in the Issues Management Systems and aligned with the LLNS Assessment Program. Linkages between all of these elements of CAS through common functional areas will aid efforts to integrate.

- It is critical that the SBMS provides a clear vehicle to identify the exact requirements from each source document (e.g., a DOE Directive) and further align those requirements with the LLNS implementing procedure or procedures that enable compliance. This is generally most useful when the alignment is specific to the part or section of the procedures that enable compliance. This approach not only provides a highly visible trail for internal or external entities to reach conclusions on process/procedure adequacy, but it also provides a powerful configuration management tool when procedure authors are revising procedures. Steps in the LLNS process for revising procedures should include assurance that any change still enables compliance with ALL associated requirements.

- LLNS may find significant cost-efficiencies in establishing institutional level common procedures for particular activities, rather than similar procedures that are generated under each or some Principle Associate Director(s). Single common procedures are naturally less expensive to maintain and are not subject to differing specification and interpretation that naturally occur under multiple similar procedures. As many procedures as possible should be included in the institutional level set. (When moving to institutional level procedures, ensure that any impacts on nuclear facility documented safety bases are understood ... some procedures may be incorporated by reference into these documents.)

\section{Risk Methodology}

The CAS Implementation Plan discusses an initiative for LLNS to define a risk methodology which will include Risk Analysis (i.e., consequence of failure and probability of failure) and Risk Management. Based on the risk level from the analysis a course is determined to manage the risk. These concepts are proven and appropriate but trying to apply the detailed model to every issue, change, and work activity may not be practical. 
Suggestions for improvement:

- These somewhat detailed concepts should be applied when warranted as opposed to globally applied to all issues, all changes, and all work activities. For example, many issues that get identified in the Issue Management System should already get categorized based on a risk (or significance) category that is already imbedded as part of that process. Therefore, expending energies to further profile such issues through a formal Risk Analysis may not be cost-effective, and probably will not result in different treatment under the corrective action program. Similarly, all changes to requirements may not involve the need to specifically analyze the consequence of failure and probability of failure in any amount of detail. Therefore, LLNS should consider tailoring the use of the detailed Risk Methodology when it will provide value to decision making with respect to the path forward.

- Consider imbedding risk (or significance) factors in the various processes. For example, assessment frequencies can be based on facility operations risk (Hazard Category 2, Hazard Category 3, radiological) and performance.

\section{Continuous Improvement}

LLNS has started the early implementation stages for continuous improvement. A Continuous Improvement Manager has been identified within the CAS Organization, but the CAS Implementation Plan does not include any information on continuous improvement, process improvement, or the implementation of Lean Six Sigma at LLNL. Therefore, most of the information related to continuous improvement was obtained through interviews.

Some positive program elements were noted:

- Three Six Sigma Black Belt candidates have been selected and trained, and certification is expected in February 2008. The candidates began their training in June 2007. Three Process Improvement Projects (PIPs) are nearly complete, with another three PIPs in progress. The Black Belt candidates are known as Process Analysts and appear very well qualified and well suited for their process improvement role. It is notable that all three Process Analysts attended a two week training session in Six Sigma tools and methods (Define, Measure, Analyze, Improve and Control) in September 2004 through the Atomic Weapons Establishment in the United Kingdom and have been using this methodology to conduct process improvements at LLNL since that time.

- The Process Analysts provided training on Six Sigma tools and methods to over 100 people from late 2006 through July 2007. The courses offered included Mapping and Measurements (two day course for process owners, line managers, and IT managers), Beyond Mapping (one day course for Joint Genome group), Balanced Scorecard (a two day course on metrics), LLNL Performance Metrics (two day course), and a three hour course on Performance Improvement Concepts and Tools.

- The academic culture at the laboratory is well suited to use of the Six Sigma tools, as most of the employees are receptive and used to the practice of collecting and using data to make decisions. Many parallel initiatives with similar concepts (such as ISO 9000) have been embraced at the Laboratory and used with good success. Six Sigma concepts have 
been used at NIF to improve several processes in the past. In general, employees are interested in improving performance and efficiency. The LLNL management team and Process Analysts have a good feel for the culture of the laboratory, and the Process Analysts have a good working relationship with several groups. This will provide a good means for promoting use of Six Sigma and Lean methodologies for process improvement.

- A Process Improvement Portal (web site) is in place. The web site is well designed and user friendly, and contains information on previous process improvement projects conducted at the laboratory. This could be easily updated and expanded to provide a communication tool on future process improvement activities. A link to the home page should be provided to make this web site easier to find.

\section{Suggestions for improvement:}

As LLNS pursues implementation of its Continuous Improvement Program, the team suggests the following recommendations be given consideration:

\section{- Black Belts}

- Black Belts should be a full time assignment. Currently, one of the Black Belts is not full time in this role (he currently holds a manager position in Property Management). Typically, a two year commitment after certification is required to justify the investment in training and certification of the Black Belts.

- Black Belts should report to the Continuous Improvement Manager for consistency in direction. Currently they report to various managers. In addition, it is recommended that the Black Belts be located in the same office building, so that they can share information and ideas. It is important that they be available to support any organization at LLNL, and not be dedicated to a single directorate, so that they can support those projects that are of the greatest importance to the entire laboratory.

\section{- Maximize Utilization of Existing Resources}

- There are currently some individuals with Six Sigma training at the Laboratory (e.g. Champion, Green or Yellow Belt, or Black Belt). These individuals should be identified and mapped to their current organizations. This effort will provide a list of existing resources and identify areas where additional Champions and Yellow Belts are needed. If the existing "belts" can not be used as Yellow or Green Belts due to their current job responsibilities/positions, they should be used as Champions.

- There are several organizations that have embraced the idea of process improvement and have utilized various tools and methods to improve efficiency and reduce defects. These organizations could be used to introduce, foster and demonstrate successes using the Six Sigma methodologies.

- Utilize the existing Six Sigma expertise at the lab in developing the implementation plan. Some resources are Craig Barnes, Quality Assurance Manager, and Paul Rosenkoetter, in the Operations and Business Directorate. Both these individuals have several years of hands-on experience in developing and managing Six Sigma Programs at DOE and DOD sites. Other resources will be identified when the 
existing staff with Six Sigma training or experience are identified and mapped to the existing organizations.

- Establish a Six Sigma Oversight Committee (SSOC), preferably using an existing Senior Management committee/council. Functions of the SSOC are to prioritize the Process Improvement Projects (PIPs) to be worked by the Black Belts, approve Business Cases, authorize funding for Six Sigma training, and approve PIP team recommendations prior to implementation. It was suggested that the Operations Council may be the right group for this function. The Deputy Laboratory Director should be on the council, along with key Senior Management.

\section{- Training}

- Consider sending one of the Process Analysts (Black Belts) to the Bechtel-sponsored Design for Six Sigma training planned for the first Quarter of 2008 (estimated date is late February or March 2008). There is a significant need for integration of processes across the 13 directorates and the Design for Six Sigma tools are well suited for developing processes that do not currently exist as well as those that need to be redesigned from scratch.

- Develop in-house capability for providing Six Sigma Champion and Yellow Belt training. The size of the laboratory will support a need for many Yellow Belts and Champions, and it would be cost effective to provide this training on-site and in house. As an example, LANL has over 100 Yellow Belts, and Nevada Test Site had 180. The size and complexity of the laboratory would also support the need for a Master Black Belt or an individual with a similar strong Six Sigma background and expertise to provide mentoring and guidance for the Black Belts and Yellow Belts.

- There are many on-line training courses in Bechtel University on Six Sigma and Lean concepts. Some good introductory courses are SSB-301, 302, 303 (Six Sigma, and SSB- $342-344$ (Lean). A target audience should be identified for these courses, and they could be identified as required training for these individuals. The courses average an hour in length. Access will need to be set up for the target audience.

\section{- Identification and Prioritization of PIPs}

- A Strategic Gap Analysis should be conducted against the laboratory's goals and objectives for the next year to identify gaps and areas where process improvements are needed. The Multi Year Improvement plan will also identify areas for process improvement.

- Look for some quick wins - "low hanging fruit". (Processes that everyone agrees need improvement, that are often used by many will yield the greatest benefits).

- The company level and directorate level performance measures, assessment results, and other information gathered by the CAS org should be reviewed on a regular basis to identify areas where there may be need for a Six Sigma PIP or Lean event. The Bechtel Six Sigma Procedures provide guidance on the recommended approach for identifying and approving PIPs. 


\section{- Other Recommendations}

- Additional Black Belts will be needed at the project. However, it is recommended that the project first focus on identifying and training Champions and Yellow Belts to establish process management systems and develop business cases for the Process Improvement Project (PIP) pipeline. The project should initiate selection of the next round of Black Belt candidates approximately three months in advance of the next scheduled training session for Black Belts.

- The impending budget cuts and reduction in force will present a challenge for deployment of Lean and Six Sigma methodologies. Caution must be exercised in selection of PIPs and communication of PIP results so that managers and employees do not perceive Six Sigma as a tool for identifying where reductions in force are needed, but rather as a tool to identify ways that the laboratory processes can improve efficiency and continue to meet customer requirements despite the unavoidable reductions in force. If people believe that PIPs will result in layoffs, it will not be long before there are no more suggestions for process improvements. This is a lesson learned from other DOE sites. Six Sigma should be viewed as a tool set to improve efficiency so that we can still get the work done, given the need to do it with fewer resources.

- A process for validating PIP cost savings will need to be established, using expertise from the Finance organization. The Bechtel Six Sigma Financial Measurement, Reporting and Planning Guide provide useful information on how this should be done.

\section{Governance and Customer Transparency}

Governance and Customer Transparency were only touched on during the review. Many of the initiatives for other CAS elements/attributes are supportive of improved Governance and Customer Transparency and the CAS Implementation Plan initiatives seemed to be on target for these attributes. Continued attention should be given to ensure the LLNS CAS provides input to support the LSO oversight model.

\section{Other Areas of Interest}

The team did not perform any specific review of the CAS Event Reporting, Worker Feedback Mechanisms, and Lessons Learned elements, as other than ownership, sponsorship and advocacy interests, as appropriate, through the Contractor Assurance Office, no plans or instruments for specific improvement were identified by LLNS in these areas.

The use of Assurance Managers as a means to a consistent roll-out and implementation of improvements is a sound practice. Each Directorate, as a minimum should have an Assurance Manager who is trained in all the CAS processes and is knowledgeable of how there are to be used by LLNS to improve performance. 
A special thanks to those interviewed for taking the time from there busy schedules. The individuals interviewed by the team members were knowledgeable and offered open and candid insights into the areas being reviewed. 


\section{Attachment A \\ Persons Contacted or Interviewed}

Steve Johnson - Director, Contractor Assurance

Pamela Minniear - LSO

Patrick Dempsey - Deputy Program Director, Contractor Assurance and Continuous Improvement Jill Farrell - Manager, Issues Management

Kristin Ruley - Manager, Standards and Requirements

Jeff Horning - Manager, Continuous Improvement Strategy/Process Improvement

Steve Liedle - Deputy Director LLNS

Allen Macenski - Associate Director, ESH\&Q

Merna Hurd - Associate Deputy Director, Special Projects

Thomas Isaacs - Director, Planning and Special Projects

Trey Johnston - Corporate Representative, LLNS, LLC

Paul Schafer - Lab Auditor, Independent Audit \& Oversight

Glennette Alston, Manager, Training ESH\&Q

Craig Barnes, Quality Assurance Manager

Jim Merrigan, Assurance Manager, ESH\&Q

Emanual (Manny) Lateiner, Department Head, Administrative \& Operations Support

Terri Compton, ESH\&Q Office Manager

Sharon Thomas, ESH\&Q Procedure/Admin. Support

Frank Russo, Principal Associate Director for Operations and Business

Pam Horning, Deputy Principal Associate Director, Operations \& Business

Harold Conner, Associate Director for Facilities and Infrastructure

Jerry Paulson, Associate Director for Nuclear Operations

Robert C. Bills, Department Head, Human Resource Services

David Leary, Associate Director, Business and Deputy PAD, Operations and Business Monya Lane, Deputy Associate Director, Engineering

Al Moser, Deputy CFO, Corporate and Institutional Services 


\section{Attachment B \\ Documents Reviewed}

LLNS CAS Description Document dated July 9, 2007

LLNL Contactor Assurance Implementation Analysis Reference Documents, Attachment 2 dated October 1, 2007

LLNL Metrics - LLNS Dashboard briefing Jill Farrell (Development philosophy, Current State, Future plans)

Assessment Process - improvement Timeline briefing, Patrick Dempsey (12/4/07)

Issues Management, Jill Farrell (12/12/07)

LLNL organization charts (10/01/07)

Assurance Manager Function R2A2s

LLNL Issues Management Process, draft flowchart

Process Improvement Project Information Flow, draft

ABMS New Requirement Process, Rev 11

CAS Implementation Plan, Final

Process Improvement Web Site

ES\&H Manual (on-line)

Contractor Assurance Implementation Analysis Reference Documents

Process Improvement Presentations by Black Belt candidates

Contract Requirements

PEP requirements 